\title{
Aspectos restritivos à integralidade nos Núcleos de Apoio à Saúde da Família: o olhar dos stakeholders
}

\author{
I ${ }^{1}$ João Dutra de Araujo Neto, ${ }^{2}$ Izabelle Mont'alverne Napoleão Albuquerque, \\ ${ }^{3}$ Geison Vasconcelos Lira, ${ }^{4}$ Maria Lúcia Magalhães Bosi I
}

Resumo: Os Núcleos de Apoio à Saúde da Família (Nasf) visam ampliar e qualificar açôes junto à Estratégia de Saúde da Família (ESF), contribuindo para consolidar os princípios do Sistema Único de Saúde (SUS), a exemplo da integralidade, que ainda se depara com muitos desafios, um dos quais é a cultura organizacional. O objetivo deste estudo foi analisar os aspectos restritivos ao princípio da integralidade. Trata-se de um estudo avaliativo, orientado pelo enfoque de quarta geração, tendo como cenário um município do Nordeste do Brasil; envolveu gestores, profissionais do Nasf, profissionais da ESF e usuários, totalizando 27 participantes. Para a construção do material discursivo, utilizamos entrevistas semiestruturadas, operacionalizando o Círculo Hermenêutico-Dialético.

O material empírico deu origem a quatro categorias: fragilidade do vínculo com o território; desafios do trabalho em equipe multidisciplinar; falta de competências para a atuaçáo no Nasf; e deficiência de apoio logístico. Evidencia-se como fator restritivo de destaque à atuação do Nasf concernente à integralidade a fragilidade do vínculo entre as equipes de saúde e destas com a população, além da falta de competências dos profissionais, cuja importância se expressa nos resultados.

> Palavras-chave: avaliação em saúde; integralidade em saúde; atenção primária à saúde.

\author{
1 Universidade Federal do \\ Ceará. Fortaleza-CE, Brasil \\ (joaodutrafisio@gmail.com). \\ ORCID: 0000-0002-6436-9486 \\ 2 Universidade Estadual Vale \\ do Acarau. Sobral-CE, Brasil \\ (izabellemontalverne@gmail.com). \\ ORCID: 0000-0003-0856-5607 \\ ${ }^{3}$ Universidade Federal do Ceará. \\ Sobral-CE, Brasil (vasconlira@ \\ gmail.com). \\ ORCID: 0000-0001-7623-0652 \\ ${ }^{4}$ Universidade Federal do Ceará \\ Fortaleza-CE, Brasil (malubosi@ \\ ufc.br). \\ ORCID: 0000-0001-9742-9230
}

Recebido em: 23/12/2017 Revisado em: 23/07/2018 Aprovado em: 08/10/2018 


\section{Introdução}

Nos últimos anos, o Sistema Único de Saúde (SUS) vem mostrando significativos avanços, entre eles, a expansão do número de equipes de saúde da família no contexto da Atenção Básica à Saúde (ABS), com melhorias na assistência e em seus mecanismos gestores. No entanto, tem se revelado ainda insuficiente, quer pela abrangência de suas práticas, quer pela pouca resolubilidade em observância ao princípio da integralidade (CONASEMS, 2011).

Segundo Starfield (2002), a integralidade pode ser entendida a partir de diversos ângulos não excludentes entre si, mas que destacam aspectos diversos da mesma questão, podendo ser compreendida como "atendimento integral", focando prioritariamente as atividades preventivas e de promoção da saúde, sem prejuízo dos serviços assistenciais, configurando-se como um dos atributos próprios da ABS. A integralidade na atenção à saúde extrapola a estrutura organizacional hierarquizada e regionalizada da assistência à saúde, se prolonga pela qualidade da atenção individual e coletiva assegurada aos usuários do SUS e requisita o compromisso com o contínuo aprendizado e com a prática interdisciplinar (MACHADO et al., 2007).

Merhy (2002) aponta que a ABS demonstra ser um elemento-chave na constituição dos sistemas nacionais de saúde, com capacidade de influir nos indicadores e com grande potencial regulador da utilizaçáo dos recursos de alta densidade tecnológica, buscando garantir o acesso universal aos serviços que tragam reais benefícios à saúde da população. Contudo, discussōes a partir da expansão das equipes de saúde da família que englobam a reflexão crítica sobre as práticas desenvolvidas na $\mathrm{ABS}$ fundamentam a consideração de que o fenômeno isolado de expansão do número de equipes implementadas até então não garante a construção de um novo modelo de saúde pautado na integralidade (CONASEMS, 2011; HENRIQUE; CALVO, 2009).

Nesse contexto, objetivando ampliar a abrangência e a resolubilidade das açóes de saúde no âmbito da ABS, o Ministério da Saúde (MS) criou o Núcleo de Apoio à Saúde da Família (Nasf), com a finalidade de apoiar a inserção da Estratégia de Saúde da Família (ESF) na articulação das Redes de Atenção à Saúde (RAS) e intensificar açôes interdisciplinares, contribuindo assim com a busca da integralidade na atenção à saúde (BRASIL, 2012a; BRASIL, 2009).

A proposta do Nasf visa à ampliação e à qualificação das açôes de saúde, contribuindo com a observância do princípio da integralidade. Entretanto, o seu 
grande desafio é a mudança de uma cultura organizacional no SUS, que prioriza a quantidade em detrimento da qualidade da assistência prestada-uma situação desejável e até presente no discurso oficial, mas que não acontece de forma espontânea, nem a curto prazo, sem uma focalização nessa dimensão.

Sabe-se que o monitoramento e a avaliação de políticas, programas e estratégias de saúde são de extrema importância para o seu aperfeiçoamento (DESLANDES; IRIART, 2012). Porém, a proposição e a adoção de mudanças não são metas simples e requerem bastante envolvimento de todos os implicados no processo. Para isso, conhecer as circunstâncias e o contexto em que se inserem as ações é fundamental, principalmente no que diz respeito ao comportamento e às percepçóes dos atores envolvidos (NOGUEIRA-MARTINS; BÓGUS, 2004).

Nessa lógica, é necessária uma abordagem ampliada, que inclua "os porquês" e o "como fazer" do processo, de forma contextualizada e com a participação de todos os implicados - no caso em tela, com o Nasf. Porém, ainda encontramos na literatura uma deficiência de estudos voltados a processos avaliativos do Nasf com tais características, capazes de identificar, analisar e propor alteraçôes que possam melhorar as açóes de saúde realizadas pelo mesmo, com ênfase na integralidade das açôes em saúde.

É nesse contexto que se justifica o presente estudo, fundamentado em um processo avaliativo responsivo e construtivista do Nasf, consoante o enfoque avaliativo de Quarta Geração (Fourth Generation Evaluation). Para tanto, operacionalizamos o Círculo Hermenêutico-Dialético (CHD) (GUBA; LINCOLN, 2011), visando a avaliar a atuação do Nasf quanto ao princípio da integralidade, buscando identificar os aspectos restritivos, na perspectiva dos diferentes grupos de interesse (stakeholders).

Considerada uma geração de ruptura e alternativa às geraçóes anteriores tradicionais, com foco no paradigma positivista, a avaliação de quarta geração caracteriza-se por não estabelecer a priori parâmetros ou enquadramentos. Estes são definidos através de um processo de negociação, com base nas Reivindicações, Preocupaçóes e Questóes (RPQ) dos grupos de interesse servindo de foco organizacional na determinação de quais informaçôes são relevantes, sugerindo uma avaliação responsiva e implementando-se pelos pressupostos metodológicos do paradigma construtivista (GUBA; LINCOLN, 2011). 


\section{Atenção Básica em Saúde no Brasil}

De acordo com a Declaração de Alma-Ata, a Atenção Primária à Saúde (APS), ou Atenção Básica em Saúde (ABS), como tem sido preferencial, mas não exclusivamente, denominada no Brasil, corresponde aos cuidados essenciais, baseados em tecnologias acessíveis, que levam os serviços o mais próximo possível dos lugares de vida e trabalho das pessoas, constituindo assim o primeiro nível de contato com o sistema nacional de saúde e o primeiro elemento de um processo contínuo de atenção (OMS, 2008). Sem pretender retomar a discussão desenvolvida na literatura (CECILIO et al., 2012; GOMES et al., 2011) atinente ao emprego de cada terminologia, neste artigo empregaremos o termo Atenção Básica em Saúde (ABS), dada sua adoção nos espaços institucionais e nos documentos técnicos no setor.

Para Starfield (2002), a ABS forma a base e determina o trabalho de todos os outros níveis dos sistemas de saúde, promovendo a organização e racionalização da utilização dos recursos, tanto básicos como especializados, direcionados para a promoção, manutenção e melhoria da saúde.

$\mathrm{NaESF}$, o trabalho em equipe é considerado um dos pilares para a mudança do atual modelo hegemônico em saúde, com interação constante e intensa de trabalhadores de diferentes categorias e com diversidade de conhecimentos e habilidades que interagem entre si para que o cuidado do usuário seja o imperativo ético-político que organiza a intervenção técnico-científica (STRALEN et al., 2008; COSTA et al., 2009). Tal estratégia, no plano discursivo, incorpora os princípios do SUS e desponta como um novo paradigma na atenção à saúde, com diretrizes inovadoras na forma de produzir as açôes e serviços de saúde, na perspectiva de mudança e conversão do modelo assistencial mecanicista e biomédico (CECILIO et al., 2012).

A Política Nacional de Atenção Básica (PNAB) expressa e enfatiza a posição da ABS como porta de entrada preferencial do SUS e ponto de partida para a estruturação dos sistemas locais de saúde, destacando o modelo de atenção e a definição de prioridades: consolidar e qualificar a ESF como modelo de atenção básica e centro de reordenação das redes de atenção à saúde no SUS, com equipes multiprofissionais responsáveis pelo acompanhamento de um número definido de famílias, em áreas geográficas delimitadas (BRASIL, 2012a). 


\section{Limites e desafios da integralidade no contexto da ABS}

Estudos realizados desde a década de 1990 vêm apontando importantes desafios para a consolidação de um modelo assistencial com bases na ABS, dentre os quais se destacam a capacidade gestora dos municípios, o vínculo dos profissionais e, ante a incipiente definição de redes regionalizadas de atenção à saúde, o desafio de ofertar cuidados contínuos e coordenados com observância ao princípio da integralidade (HEIMANN et al., 2011).

O termo integralidade vem sendo correntemente utilizado para designar um dos princípios do SUS, compreendido como a assistência à saúde abrangendo tanto as ações assistenciais ou curativas quanto, e prioritariamente, as atividades de promoção da saúde e prevenção de doenças, considerado assim como um dos atributos-chave da ABS. Essa, entretanto, seria apenas uma das dimensôes do conceito de integralidade (STARFIELD, 2002; SALA et al., 2011).

Outro ângulo de aproximação com a integralidade considera a rede de serviços com distintos níveis de complexidade e de competências em que a integração entre as açôes se realiza e satisfaz o conjunto de cuidados demandados por um indivíduo. Intervém agora a atuação decisiva dos gestores que organizam o conjunto dos serviços de saúde e que estabelecem articulaçôes favorecedoras de uma "integralidade vertical”, entre os diferentes níveis de complexidade e competência de uma rede de serviços de saúde (MATTOS, 2004).

No âmbito da prática profissional, Sala et al. (2011) apontam a integralidade como valor a ser sustentado e defendido nas práticas dos profissionais de saúde, ou seja, um valor que se expressa na forma como estes respondem aos usuários que os procuram. Bosi e Uchimura (2006) afirmam que, tomada como princípio norteador da avaliação de programas de saúde, a integralidade pode ser concebida como princípio orientador das práticas, ou orientador da organização do trabalho, ou ainda, orientador da organização das políticas, mas, acima de tudo, implica uma recusa ao reducionismo, uma recusa à objetivação dos sujeitos e uma afirmação da abertura para o diálogo.

A expansão da ESF tem favorecido a equidade e universalidade da assistência, uma vez que as equipes têm sido implantadas, prioritariamente, em comunidades antes restritas quanto ao acesso aos serviços de saúde. Entretanto, dada sua multidimensionalidade, não se pode admitir apenas com base em estatísticas, sem 
analisar suas práticas no contexto de trabalho, que a integralidade das açôes deixou de ser um problema no exercício da atenção em saúde na ABS (HENRIQUE; CALVO, 2009). Buscando contribuir com a integralidade da atenção e a interdisciplinaridade das açôes, identificou-se a necessidade da presença de outros profissionais de saúde integrando a ABS/ESF. Assim, no período de 1997-2006, em várias regiōes do país, foram identificadas diversas experiências de incorporação de outros profissionais de saúde (não previstos na equipe mínima) à ESF, compondo um cenário bastante diversificado (LINHARES et al., 2010; PATROCÍNIO, 2012).

Entre 2003 e 2005, constatando-se que a realidade nos serviços era distinta da idealizada, vários foram os debates relacionados a propostas de mudanças do modelo de $\mathrm{ABS}$, os quais defendiam a flexibilização de diretrizes para que a estratégia se aproximasse das diferentes realidades. Tais debates envolviam interesses múltiplos e conflitantes, perpassando por demandas que iam desde necessidades de atenção integral ao usuário até interesses corporativistas com reivindicações das diferentes categorias profissionais para inclusão de outras especialidades na ABS/ ESF (PATROCÍNIO, 2012).

Reconhecendo a importância de rediscutir a organização da ABS/ESF, os debates giravam em torno de três pontos principais: a ESF como modelo único ou a possibilidade de indução de outros modelos de atenção; a flexibilização da ESF, no que diz respeito à composição da equipe e carga horária dos profissionais; e o enfrentamento de limitaçôes no modelo de atenção vigente. A partir desses pontos, registraram-se posições favoráveis a experiências com modelos variados de ABS; no entanto, recomendou-se que tais experiências incorporassem os princípios da ESF de territorialização, adscrição de clientela e estabelecimento de vínculo (CASTRO; MACHADO, 2012).

Assim, com o objetivo de apoiar a inserção da ESF na rede de serviços e ampliar a abrangência e a resolubilidade das açôes de saúde, contribuindo com a integralidade da atenção à saúde na ABS, a Portaria GM no 154, de 24 de janeiro de 2008, criou o Nasf (BRASIL, 2009).

\section{Núcleos de Apoio à Saúde da Família}

Como apontado anteriormente, o Nasf representa uma iniciativa de enfrentamento de antigas questôes, como a ampliação do escopo das açôes no âmbito da atenção básica, 
visto que grande parte dos problemas de saúde ainda não tem sido solucionada nesse nível, bem como a inclusão das especialidades médicas básicas e de outros profissionais nas equipes de $\mathrm{ABS}$, em reposta às possíveis necessidades de atenção integral e às pressóes corporativistas (CASTRO; MACHADO, 2012; NASCIMENTO, 2014).

Discussóes relacionadas à ampliação e/ou participação de outras categorias profissionais na equipe mínima da ESF configuram-se no cenário nacional desde 2003, estando presentes nas reuniōes da Comissão Intergestores Tripartite (CIT) e do Conselho Nacional de Saúde (CNS) no ano de 2004, inicialmente idealizando o Núcleo de Saúde Integral (NAI) e posteriormente desenvolvendo-se até o Núcleo de Apoio à Saúde da Família (Nasf) em 2008, quando foi publicada sua portaria. Portanto, se trata de um dispositivo resultante de um processo político longo e complexo, permeado por tensôes de várias ordens e mediações, até a constituição de uma nova proposta de atenção à saúde (PATROCÍNIO, 2012).

O Nasf foi construído como uma proposta que atendesse a interesses múltiplos e conflitantes no interior do MS, sem modificar o modelo de organização da ESF já existente, sendo considerada uma saída virtuosa para as discussões entre os grupos de poder com posiçóes diferentes. Assim, o Nasf possibilitou a reafirmação da ESF com os moldes iniciais de porta de entrada e o atendimento a uma série de interesses expressos nos debates naquele momento, sendo considerada uma iniciativa com potencial de promover a integração do modelo de atenção preconizado e as inovaçóes mais expressivas da ABS no referido período (NASCIMENTO, 2014).

Apesar de admitir a importância da inclusão de outras categorias profissionais nas equipes de $\mathrm{ABS}$, o MS preconizou o Nasf como equipe de apoio matricial, e não como porta de entrada para o sistema, mantendo a porta de entrada por meio da equipe mínima da ESF, uma alternativa à "flexibilizaçáo" da composição das equipes de $\mathrm{ABS}$, e possibilitando o atendimento às demandas de diferentes corporaçóes da saúde que estavam reivindicando sua inserção na ESF, contando com rápida adesão municipal em vários estados desde o primeiro ano de implantação (CASTRO; MACHADO, 2012).

Como já aludido, os Nasfs têm como fundamento a integralidade do cuidado aos usuários, orientando-se por um conceito ampliado de saúde que ultrapassa o plano biológico, modelo que deve ser considerado na atuaçấo dos profissionais. Isso impóe repensar a formação e as práticas em saúde vivenciadas até o momento pela ESF e traz como ferramentas instituídas em suas diretrizes a Clínica Ampliada, 
o Apoio Matricial, a Interconsulta e o Projeto Terapêutico Singular (PTS) para a realização do cuidado ao usuário e qualificação das açóes das equipes (BRASIL, 2014; SILVA et al., 2012).

Em 21 de outubro de 2011, foi publicada a Portaria no 2.488 do MS, com a instituição de nova edição da Política Nacional de Atenção Básica (PNAB), na qual se insere oficialmente o Nasf junto à $\mathrm{ABS}$ e reafirma a mesma como principal nível de coordenação da integralidade nas açôes de saúde, ressaltando a importância do trabalho em equipe, multiprofissional e interdisciplinar (BRASIL, 2012a).

No contexto da ABS, o Nasf deve buscar qualificar e complementar o trabalho das ESF, atuando de forma compartilhada para superar a lógica fragmentada ainda hegemônica no cuidado à saúde, visando à construção de redes de atenção e cuidado, e colaborando para que se alcance a plena integralidade do cuidado físico e mental aos usuários do SUS (BRASIL, 2009). Porém, ao analisarmos como a literatura tem explorado esse tema, foi possível observar que a grande maioria das publicaçóes se refere ao processo de implantação e/ou expansão do Nasf, com ênfase em uma área de atuação específica, relacionada na maior parte das vezes à inserção de uma classe profissional no contexto da ABS. Por outro lado, identificamos um número reduzido de trabalhos com foco em temáticas como o trabalho em equipe multi e interdisciplinar e suas diretrizes de trabalho, caracterizando uma carência de estudos avaliativos capazes de discutir com a devida profundidade suas dificuldades e potencialidades no que concerne à integralidade (ANDRADE et al., 2012; BARBOSA et al., 2010; LIMA et al., 2012; LINHARES et al., 2010; MOLINIAVEJONAS et al., 2010; SANTOS; LACAZ, 2012; SILVA et al., 2012).

\section{Avaliação: da mensuração de atributos à negociação com os stakeholders}

Guba e Lincoln (2011) dividem historicamente os modelos avaliativos em três geraçôes e defendem que, com o passar do tempo, a construção da avaliação se tornou mais fundamentada e esclarecida, a ponto de conceberem uma construção radicalmente nova, que os mesmos denominaram "Avaliação de Quarta Geração".

Os autores mencionam que cada geração representou um passo adiante, tanto em relação à variedade de sentidos ou conteúdos incluídos na construção defendida quanto a seu nível de sofisticação. A coleta de dados não era sistematicamente possível 
até o desenvolvimento de instrumentos apropriados, o que caracterizou a primeira geraçáo. Mas a avaliação teria estagnado nesse ponto se a segunda geração não mostrasse formas de avaliar aspectos como programas, estratégias de ensino, padróes organizacionais e "abordagens" em geral. A terceira geração exigiu que a avaliação julgasse tanto o mérito do objeto de avaliação (seu valor íntimo e intrínseco) como a sua importância (seu valor extrínseco ou contextual). No entanto, segundo eles, as três geraçôes, como um todo, sofreram e continuam sofrendo com algumas imperfeiçôes ou defeitos, suficientemente graves para justificar que se questione se não seriam indispensáveis outros aprimoramentos ou mesmo uma completa reconstrução.

A partir das críticas apresentadas, Guba e Lincoln (2011) propóem uma nova construção, que a caracteriza como Avaliação de Quarta Geração, uma ruptura epistemológica com os referenciais anteriores, com a qual acreditam responder às imperfeiçôes e dificuldades neles detectadas. Trata-se de um modelo de avaliação em que as Reivindicaçóes, Preocupaçóes e Questóes (RPQs) dos grupos de interesse (Stakeholders) servem como enfoques organizacionais (princípios para determinar quais informaçóes são essenciais), implementados de acordo com os preceitos metodológicos do paradigma de investigação construtivista.

Para os autores, a avaliação de quarta geração é uma construção social em que são levados em conta os contextos, a negociação, o envolvimento dos participantes interessados (stakeholders), a construção social do conhecimento e os processos cognitivos, sociais e culturais (avaliação como negociação), devendo-se utilizar métodos predominantemente qualitativos, não se pondo à parte a utilização de métodos quantitativos. Eles afirmam que a avaliação deve servir mais para ajudar as pessoas a desenvolverem as suas aprendizagens do que para julgá-las ou classificalas numa escala.

Ante o exposto, elegemos o enfoque avaliativo de quarta geração para desenvolver esta pesquisa, de contornos avaliativos, acerca dos entraves que se apresentam à implantação e consolidação do Nasf em suas interfaces com a integralidade do cuidado. Ao fazê-lo, não desconhecemos as vicissitudes presentes em qualquer processo avaliativo. $\mathrm{Na}$ impossibilidade de submeter o modelo a uma análise crítica densa, objeto que escapa aos limites deste artigo, torna-se oportuno, ao menos, evidenciar alguns aspectos concernentes à necessária discussão desse modelo. De início, cabe assinalar que foi preciso submeter todas as etapas desta pesquisa avaliativa à necessária reflexividade (BOOT, 2010), haja vista o caráter hermenêutico do 
modelo de quarta geração, que inclui produçôes subjetivas e alteridades em tensão, não se configurando, portanto, como tecnologia isenta e axiologicamente depurada.

É preciso desfetichizar a suposta quarta geração como intrinsecamente isenta de vícios; mais que isso, reconhecer que, sendo uma trajetória antecedida por outros modelos, grosso modo, nos processos avaliativos podem incidir traços das geraçóes (nos termos dos autores) anteriores, ao tempo que não pode ser tomado como última, única ou definitiva resposta, não obstante seus avanços potenciais. Consoante Furtado (2001:167) referindo-se à construção de Guba e Lincoln (2011), "essa divisão em geraçôes de avaliadores é essencialmente didática e na realidade os diversos referenciais de avaliação coexistem, calcados em diversos eixos metodológicos”. O mesmo autor assevera que "o caráter político das práticas avaliativas é inegável e o afloramento de jogos de poder onde estas se realizam é frequente, o que requer do avaliador atenção constante de modo a evitar cumplicidades de diversas ordens ou que se venha a sucumbir a pressôes políticas e administrativas".

Os desafios presentes em qualquer processo avaliativo não se ausentam na assim chamada "quarta geração", a começar pela posicionalidade (EAKIN, 2010) do avaliador e os aspectos ético-políticos (CARVALHO; BOSI, 2016) implicados que poderão incidir, por exemplo, no privilégio de um grupo sobre os demais na etapa de negociação. Quanto a isso, Campos (2000) sinaliza a necessidade de, nos processos avaliativos, romper com a endogenia e inserir certo grau de externalidade ao processo possibilitado por elementos materiais e novos atores como apoiadores. Estes, a nosso ver, poderiam em certa medida diluir o peso da figura do avaliador no formato da quarta geração.

Conforme sinaliza Furtado (2001), facilita-se "a superação dos riscos de reiteraçóes, autorreferências e pontos cegos presentes no círculo hermenêutico proposto por Guba e Lincoln (2011)". Contudo, e não obstante essas ressalvas e muitos outros aspectos que poderiam ser acrescentados, são inegáveis os avanços dos assim chamados "enfoques emergentes" (Bosi e Mercado, 2010) sobre os modelos precedentes, o que nos conduziu a operacionalizá-los neste estudo.

\section{Metodologia}

Trata-se de estudo avaliativo orientando pela abordagem qualitativa, conforme já aludido, fundamentado no enfoque avaliativo de quarta geração, por meio da 
aplicação do Círculo Hermenêutico Dialético (CHD). A opção pela referida abordagem teórico-metodológica permitiu uma aproximação da mesma com o objeto de estudo, uma vez que a aplicaçáo do CHD possibilitou realizar um processo avaliativo responsivo e construtivista do Nasf, desdobrando-se na compreensão do objeto avaliado e das construçóes dos sujeitos envolvidos.

Realizou-se no município de Sobral, no Ceará, o qual constitui cenário de referência para a Região Nordeste do Brasil no que concerne à singularidade e às inovaçôes do seu modelo técnico-assistencial e construção da integralidade em saúde (LINHARES et al., 2010). Os participantes foram 27 atores envolvidos, direta ou indiretamente, nas açóes do Nasf, os quais, segundo Guba e Lincoln (2011), foram identificados como os chamados grupos de interesse (Stakeholders), a saber: gestores (6); profissionais do Nasf (6); profissionais da ESF (6) e usuários assistidos pelo Nasf (9), dando origem a quatro CHD.

Seguindo o referencial teórico-metodológico proposto, a aplicação dos CHD com os diferentes grupos de interesse ao mesmo tempo permitiu a inclusão gradual de novos respondentes nos respectivos grupos, à medida que foram surgindo Reivindicaçôes, Preocupaçôes e Questōes (RPQ) que demandavam a necessidade de maior esclarecimento e/ou confirmação. A inclusão de novos respondentes foi interrompida quando chegamos a um ponto de equilíbrio entre a saturação de algumas RPQ, as quais foram satisfatoriamente esclarecidas, e o excesso de outras RPQ apresentadas, o que poderia vir a inviabilizar nossa capacidade de análise e discussão do material coletado com a profundidade e clareza exigidas.

$\mathrm{Na}$ lógica de aplicação dos $\mathrm{CHD}$, a técnica utilizada para a obtenção do material foi a entrevista semiestruturada e, concomitantemente a essa, como previsto nessa abordagem, realizou-se a análise do material empírico coletado. Para a análise dos dados, optou-se pela análise de discurso, na modalidade temática (MINAYO, 2007), técnica que consiste em descobrir os núcleos de sentido (núcleos temáticos) que representam as unidades de significação, as quais definem o caráter do discurso e que em nosso estudo expressam as RPQ dos grupos de interesse.

O estudo foi realizado de acordo com a resolução no 466/2012 do Conselho Nacional de Saúde (CNS) e aprovado pelo Comitê de Ética em Pesquisa (CEP) da Universidade Estadual Vale do Acaraú (UVA), com parecer no 842.476 (BRASIL, 2012c). 


\section{Resultados e discussão}

Nossos resultados representam parte de uma pesquisa mais ampla, abordando as RPQ manifestadas pelos diferentes grupos de interesse participantes do estudo, o qual focalizou não somente as RPQ consensuais, como também vários dissensos relativos a determinado grupo, algo esperado em se tratando de grupos diferentes, com distintas inserçôes no processo de cuidado em saúde. É preciso esclarecer que, dados os limites de espaço, este artigo focaliza apenas as preocupaçóes, que foram traduzidas como aspectos restritivos à atuação do Nasf quanto ao princípio da integralidade na ABS.

Especificamente neste ponto em particular, houve consenso entre os grupos de interesse. Não foram observados entre os grupos dissensos relativos aos aspectos que restringem a atuação do Nasf quanto ao princípio da integralidade. As interfaces do material empírico com o referencial teórico-metodológico que sustenta o presente estudo possibilitaram evidenciar preocupaçóes consensuais expressas nos discursos dos stakeholders, ainda que manifestadas em repertórios distintos. A categorização de tais aspectos restritivos mediante a análise hermenêutica deu origem a quatro categorias: fragilidade do vínculo com o território; desafios do trabalho em equipe multidisciplinar; competências para a atuação no Nasf/ABS; e deficiência de apoio logístico.

Essas categorias representam o consenso entre os stakeholders, quando as preocupações surgiram espontaneamente nas falas dos sujeitos entrevistados ou quando uma determinada preocupação apresentada era prontamente consentida pelos sujeitos que, a princípio, não a manifestaram de forma espontânea. Considerando os limites de extensão, optamos por ilustrar cada uma das categorias e dimensões analisadas com os excertos mais evocativos e representativos, valendo ressaltar que o conteúdo se reiterou em muitos outros trechos do material discursivo e que cada grupo de interesse possui sua própria linguagem e maneira de descrever a mesma dimensão mediante distintas categorias empíricas.

Para uma melhor compreensão dos resultados, os excertos apresentados foram codificados com a letra $\mathrm{R}$ e um numeral, designando a sequência de inserção dos respondentes nos CHD (R1, R2...), seguidos de sua fonte geradora (Gestão, Nasf, ESF ou USU). 


\section{Fragilidade do vínculo com o território}

De forma bastante expressiva e consensual, os stakeholders apontaram a fragilidade do vínculo do Nasf com as equipes de ESF e, principalmente, com a comunidade, como o principal aspecto restritivo para a atuação do mesmo quanto ao princípio da integralidade. Diversos foram os temas abordados como justificativa para tal fragilidade, com destaque para o número de territórios vinculados a uma equipe de Nasf, ocasionando uma menor disponibilidade dos profissionais para um mesmo território e, consequentemente, fragilizando o vínculo com o mesmo.

[...] uma dificuldade que eu acho maior no nosso processo de trabalho é a sobrecarga de unidades. É humanamente impossível e vários outros processos dificultam por conta disso. A dificuldade maior que eu acho em relação ao trabalho do Nasf é exatamente essa (R5 - Nasf).

Uma equipe de Nasf que tem um fisioterapeuta, um psicólogo, um nutricionista [...] tem várias unidades que eles têm que dar o suporte, então esse suporte fica um pouco enfraquecido, porque ele vai estar ali poucas vezes (R2 - ESF).

[...] elas não podem vir porque têm que estar em outro local, né? Nós estamos dando graças a Deus, porque elas passaram duas semanas sem vir[...] estavam em outras áreas (R2 - USU).

Atualmente, regulamentado pela Portaria no 3.124 de 2012, a qual redefine os parâmetros de vinculação das equipes de Nasf, na modalidade Nasf-1, podem vincular-se de cinco a nove equipes de ESF (BRASIL, 2012b).

O município de Sobral conta com sete equipes de Nasf-1, porém, mesmo estando cada uma vinculada a aproximadamente nove equipes de ESF, como prevê a portaria, as equipes de Nasf estáo alocadas em média em cinco Centros de Saúde da Família (CSF). Isso justifica a preocupação dos diferentes grupos de interesse, principalmente dos profissionais do Nasf e da ESF, mas também ratificada pelos gestores e usuários participantes do estudo, uma vez que os profissionais do Nasf têm que se dividir entre os territórios, impossibilitando um apoio efetivo, favorecendo a fragilidade do vínculo com as equipes e, principalmente, com a população. Vale ressaltar que, das sete equipes, seis estáo vinculadas a territórios distritais (zona rural), o que contribui ainda mais com a fragilidade do vínculo frente às dificuldades de deslocamento das equipes.

Tal preocupação está presente em outros trabalhos na literatura abordando a atuação do Nasf na visão de gestores e profissionais (ANJOS et al., 2013; 
NASCIMENTO, 2014). Os grupos evidenciaram o desejo de estar mais presente, demonstraram que, em atividades importantes como as reuniôes e as açôes coletivas, não há como dar um suporte efetivo às equipes e ao território, o que prejudica sobremaneira o vínculo profissional.

Outro aspecto relatado por todos os grupos de interesse, apesar de os discursos apontarem para a redução de sua ocorrência nos últimos anos, foi a alta rotatividade dos profissionais do Nasf.

[...] tem a mudança de território, tem as pessoas que saem porque encontram um local onde você é bem mais valorizado, isso está acontecendo muito; então acaba que a gente não tem vínculo e eles reclamam muito; tanto a população quanto a ESF (R6 - Nasf).

[...] eu entrei aqui já está com mais de um ano e já é a segunda turma do Nasf que eu vejo aqui; quando a primeira saiu, a populaçáo sentiu muito, né, pelo vínculo (R4 - ESF).

[...] elas passam até dois anos com a gente, a gente pensando que está tudo muito bom, aí quando dá fé, tá aqui, a gente chorando aqui, elas se despedindo [...] (R9 - USU).

A literatura nos mostra que a preocupação com a alta rotatividade dos profissionais é sentida principalmente pelos usuários nos territórios, uma vez que o vínculo, quando é estabelecido, geralmente é quebrado pela saída do profissional, restringindo o cuidado integral de forma longitudinal (BONALDI; RIBEIRO, 2014; FRAGELLI, 2013).

Entre as preocupaçóes que emergiram dos $\mathrm{CHD}$, especificamente, a carga horária de 20 horas semanais junto aos territórios dos profissionais fisioterapeutas e terapeutas ocupacionais, também foi apontada pelos grupos de interesse como um aspecto restritivo para a atuação do Nasf, da mesma forma contribuindo para a fragilidade do vínculo com o território.

Eu acho que a carga horária é outra questão do Nasf, por exemplo, a gente tem profissionais de 20 horas. Então, em 20 horas a gente náo consegue resolver muita coisa, por questão de ele estar um dia num lugar; outro dia, noutro. Para contemplar todas as equipes, eu preciso estar um dia em cada equipe (R5 - Gestâo).

[...] o principal, o que me incomoda, é a carga horária, você não vê, eles vêm pouco aqui [...] muito deles só têm 20 horas por semana, [...] então atrapalha bastante, acho que eles vêm um turno por semana, não vêm nem um dia, é um turno (R1 - ESF).

[...] atender e ter que esperar uma semana para ver de novo, geralmente o fisio e a TO, como têm 20 horas no Nasf, eles têm outro emprego, então não podem estar mudando horário, às vezes perdem as rodas, perdem várias atividades por conta do outro emprego (R5 - Nasf). 
Quanto a esta questão, Barbosa et al. (2010) e Reis e Vieira (2013) apontam como um ponto crítico que dificulta a atuaçáo do fisioterapeuta e do terapeuta ocupacional na equipe do Nasf e, consequentemente, no contexto da ABS, a sua carga horária diferente da dos demais profissionais do Nasf e da ESF.

Também nessa mesma perspectiva, Leite et al. (2014) ressaltam que a diferença de carga horária entre os profissionais da mesma equipe, além de dificultar a interação e a realização de atividades compartilhadas, aumenta o estresse e a sobrecarga de trabalho principalmente para os que possuem dois vínculos.

Todos esses fatores restritivos apontados como possíveis justificativas para a fragilidade do vínculo com o território e, principalmente, com a comunidade possuem ligação direta com outra importante preocupação manifestada pelos stakeholders implicados com o Nasf: os desafios para o trabalho em equipe multidisciplinar.

\section{Desafios do trabalho em equipe multidisciplinar}

A falta de integraçáo entre as equipes de Nasf e ESF foi relatada como uma preocupação pelos grupos de interesse, uma vez que dificulta a atuação de ambas as equipes que objetivam atender o princípio da integralidade, principalmente, ocasionando falha de comunicação e, consequentemente, de planejamento e pactuaçâo das atividades a serem realizadas no território, o que é de suma importância para os processos de trabalho em equipes multidisciplinares.

[...] não há essa integração entre Nasf e equipe, a gente solicita que todo final de ano ela (ESF) faça o seu planejamento de acordo com as necessidades que ela identifica pra o próximo ano. Aí a equipe fez o planejamento dela e o Nasf fez o planejamento dele; então como é que eu sou a equipe do Nasf dentro da ESF e eu faço meu planejamento e a equipe faz o dela? (R5 - Gestão).

Também, eu acho que isso atrapalha, eu vejo isso acontecer, algumas vezes, um quer fazer uma coisa e o outro náo aceita aquilo ali, aí meio que atrapalha o andar (R5 - USU).

Além da preocupação com a relação entre as equipes de Nasf e ESF, também foi possível identificar que a dificuldade para se trabalhar em equipe não existe apenas nas relaçôes entre os profissionais de grupos diferentes (Nasf x ESF). Os sujeitos também manifestaram a preocupação quanto às dificuldades para o trabalho em equipe entre os profissionais do Nasf, dificuldades nas relaçóes de trabalho dentro da própria equipe, seja por características individuais do profissional, seja por dificuldades de adequação da disponibilidade dos mesmos dentro dos territórios. 
[...] isso dificulta muito, eu nunca consigo acoplá-los dentro da equipe porque eu nunca consigo encontrá-los ao mesmo tempo (R6 - Gestão).

[...] ele está fazendo tudo só, ele está praticamente só aqui, porque a gente não está tendo assistência dos outros, eles estão lá no posto [...] mas a gente ainda não conseguiu trazer eles para cá (R1 - USU).

Trata-se de uma das principais dificuldades relatadas na literatura, em que diversos estudos apontam que o trabalho do Nasf de fato só pode ser efetivado de forma integral se forem garantidas condiçóes para o desenvolvimento da interdisciplinaridade entre as açóes dos profissionais enquanto equipe e entre estas e as dos profissionais da ESF (ANJOS et al., 2013; NASCIMENTO, 2014; ARAÚJO; GALIMBERTTI, 2013).

As diretrizes do Nasf apontam que a integração entre os profissionais da equipe e destes com as equipes da ESF não devem se restringir e nem necessariamente requerem que todos estejam juntos o tempo todo. Porém, como uma medida para minimizar a referida dificuldade, orientam que o horário de trabalho do Nasf seja coincidente com o das equipes de ESF vinculadas, bem como há necessidade de criar espaços e momentos de encontro de todos, possibilitando uma maior integração e compartilhamento do trabalho entre os profissionais e entre as equipes (BRASIL, 2014).

Um ponto importante a ser ressaltado quanto à dificuldade para a atuação em equipe de forma interdisciplinar faz referência à formação profissional. Nesta, de um modo geral, os profissionais de saúde não recebem formação em suas graduações para trabalhar na lógica da atuação interdisciplinar e, especificamente no contexto do Nasf, na lógica do apoio matricial, além de outras questóes essenciais para o trabalho compartilhado e que são raramente aprofundadas, tais como o trabalho em equipe, o vínculo e a coordenação do cuidado, dificultando a sua prática (NASCIMENTO, 2014).

Como decorrência, dentre as preocupaçôes identificadas nas falas dos sujeitos quanto ao processo de trabalho do Nasf, também está a falta de competências profissionais para a atuação no Nasf/ABS. Isso se traduz em falta de conhecimento, habilidades e atitudes quanto às diretrizes do Nasf, refletindo diretamente no perfil desses profissionais para a atuação quanto ao princípio de integralidade na ABS. 


\section{Competências para atuação no Nasf/ABS}

A falta de competências para atuação no Nasf, bem como na ABS, está atrelada diretamente à falta de perfil profissional para a referida ação, preocupação bastante presente nos relatos dos grupos de interesse, a qual surgiu também como falta de afinidade com as propostas, apontada como um fator que atrapalha e, consequentemente, restringe sua atuação, uma vez que o profissional não se integra à equipe nem às atividades e, quando o faz, não apresenta as competências necessárias para tal.

Um dos pontos principais é a questão do perfil, porque quando você coloca dentro do território um profissional que não tem perfil, ele não vai se integrar às rodas, ele não vai se integrar aos grupos, ele não acha interessante fazer isso, ele talvez não seja consciente da importância dele tá presente nesses momentos (R6 - Gestão).

[...] você tem que gostar, para você poder fazer um bom trabalho, você tem que gostar do que faz, às vezes tem também alguns que talvez vêm só pelo dinheiro, pela necessidade, não tendo afinidade (R5 - ESF).

[...] quando a pessoa não tem afinidade para trabalhar com aquele grupo, atrapalha, porque até desestimula aqueles que não têm muita força, né? (R5 - USU).

Lacunas relativas ao conhecimento, bem como às habilidades e atitudes para atuação quanto às diretrizes operacionais do Nasf por parte dos profissionais, tanto do próprio Nasf como da ESF, são uma importante preocupação identificada nas falas dos profissionais. Tal preocupação foi expressa como falta de compreensão, bem como de adesão à proposta do Nasf, o que impacta negativamente as relaçóes de trabalho e, consequentemente, seus resultados, implicando grandes desafios, uma vez que se trata de uma proposta relativamente recente.

[...] a primeira dificuldade é a compreensão dos profissionais, aí tanto o Nasf como a ESF, para a real atribuiçâo do Nasf na ABS, compreender que o Nasf, ele vem como um apoiador, não como uma categoria profissional que está lá para atender. Então eu acho que a primeira dificuldade é essa, compreensão de ambas as partes do real papel do Nasf dentro da ESF (R5 - Gestão).

[...] eu sinto que as pessoas muitas vezes não sabem, não entendem realmente qual é a proposta do Nasf [...] um quer agir de uma forma e acredita que seja dessa forma, desse jeito, e o outro quer agir de outra [...] e realmente é um problema (R6 - ESF).

Estudos como os de Fragelli (2013) e Nascimento e Oliveira (2010) destacam que a proposta do Nasf apresenta potencial para revitalizar as competências da ABS para o alcance da integralidade da atenção; porém, necessita de reflexôes mais 
aprofundadas sobre possibilidades de aprimoramento da compreensão do processo de trabalho exigido pela proposta e, consequentemente, da atuação dentro dos princípios do apoio matricial. Nesse sentido, é importante a abordagem de estratégias que possam favorecer o melhor desempenho das competências para o trabalho e reestruturação da atuação do Nasf, buscando preparar os profissionais para a atuação quanto ao princípio da integralidade, na perspectiva do apoio matricial e da intertransdisciplinaridade, com entendimento claro das políticas de saúde e do SUS.

Por fim, uma série de preocupações, relacionadas à logística para a atuação dos profissionais juntos aos territórios, evidenciou-se no material discursivo, como aspectos restritivos da atuação do Nasf quanto ao princípio da integralidade.

\section{Deficiência do apoio logístico}

Quanto ao apoio logístico, os participantes destacaram a falta de transporte para as equipes do Nasf se deslocarem de um território para o outro, principalmente quanto ao acesso aos territórios distritais da zona rural do município, uma vez que o programa não conta com carro exclusivo da equipe para essas regiôes, ficando dependente da disponibilidade do transporte de outras equipes. Isso prejudica consideravelmente o planejamento e até mesmo o acesso aos referidos territórios.

[...] são sete territórios, inclusive tem zona rural, às vezes falta transporte para eles, tá entendendo? Um dos pontos críticos seriam os distritos (R4 - Gestão).

[...] um problema que impede muito que a gente exerça a integralidade hoje é o problema de a gente não estar tendo o carro, a gente não pode ir principalmente para os distritos [...] os locais onde a gente deve ter maior prioridade (R6 - Nasf).

[...] a moça que vinha sozinha, às vezes a gente pagava o mototáxi dela, nós se juntava, tudim dava, para ela poder vir, porque nós mesmo via a situação [...] faz aqui uma reuniāo, uma palestra e a gente junta de dois reais até dar (R3 - USU).

Outra preocupação dos stakeholders quanto à logística foi a falta de espaço físico adequado para abordagens individuais e/ou coletivas. Apesar de muitos CSF estarem sendo construídos e/ou ampliados no município, vários contando com estacionamento e miniauditório, que ampliam a oferta de espaços para as equipes, ainda é sentida a preocupação quanto à falta de áreas adequadas e direcionadas à equipe do Nasf e suas propostas de trabalho.

As preocupaçôes giram em torno de espaços para abordagens individuais dentro dos CSF com garantia de privacidade quando a situação assim exigir, bem como espaços 
coletivos adequados a práticas dos diferentes grupos, os quais geralmente acontecem em áreas cedidas e ou adaptadas dentro do território e que nem sempre estão disponíveis, acarretando constrangimento e até mesmo acidentes aos seus participantes, resultando em baixa adesão às propostas de atividade coletivas pela população.

Eu falo no sentido até para própria equipe da estratégia; a gente às vezes não tem nem onde atender e vai atender no corredor, e o Nasf, eu priorizo sempre os dias deles, porque tem a necessidade, mas falta, falta espaço com certeza, aqui na minha unidade sim, você vê que é uma casa adaptada, né? (R3 - Gestão).

[...] eu não consigo atender na integralidade o indivíduo se eu não tenho espaço pra escutá-lo. Então, assim, tem momentos que vai ser preciso eu atender só e vai ter momentos que a integralidade de toda a equipe ela tem que tá a postos. E se eu não tenho uma sala de atendimento? (R2 - Nasf).

O nosso problema aqui é às vezes que eu ainda acho é que nós não temos esse local aqui toda vida; tem dias que a gente chega aqui e elas não podem ficar porque tem reunião. Eu acredito que só vai melhorar mesmo quando nós tivermos o nosso posto com condiçôes pra gente fazer nossas reuniốes lá (R2 - USU).

Diretamente relacionada às dificuldades de operacionalização dos diversos grupos junto à comunidade, a falta de material de apoio para as atividades, somando-se à falta de um local adequado para a execução dos mesmos, relatada anteriormente, exige extrema criatividade e tempo para o planejamento das açóes a serem realizadas, justificando assim uma preocupação que também emergiu em nosso estudo, de forma consensual.

[...] eu acho que o problema talvez maior seja a logística de material, eu vou trabalhar com grupo, eu preciso ter né, se eu for trabalhar algo lúdico eu preciso ter uma cartolina, e às vezes $\mathrm{i}$

sso de fato nós não temos (R5 - Gestão).

[...] muitos grupos são mantidos por nós financeiramente, né? (R2 - Nasf).

[...] falta de material também, tipo um trabalho em grupo, não tem uma cartolina, às vezes não tem um pincel, às vezes não tem uma fita adesiva, eu acho que tudo isso acaba atrapalhando (R5 - ESF).

Diversos são os trabalhos na literatura que mencionam a falta de logística e infraestrutura como aspecto restritivo para a atuação do Nasf (NASCIMENTO, 2014; BONALDI; RIBEIRO, 2014; LEITE et al., 2014; BEZERRA, 2013). A falta de espaço físico, equipamentos e materiais de apoio para a realização de atividades pelos profissionais do Nasf nos CSF se reitera neste estudo como um dos motivos para 
a busca de recursos e equipamentos no território. Contudo, nem sempre o território consegue suprir a necessidade de um local específico para o desenvolvimento das ações, ocasionando aumento do nível de estresse da equipe e interferindo na execução das açôes e na qualidade de vida dos profissionais.

Nessa perspectiva, há uma recomendação para que os profissionais do Nasf sejam cadastrados em um único CSF, localizado, preferencialmente, dentro do território de atuação das equipes de ESF. Contudo, vale ressaltar que não é recomendada a existência de uma unidade de saúde ou serviço de saúde específico para a atuação da equipe de Nasf, uma vez que o mesmo não é porta de entrada do sistema e assim não se constitui como um serviço com espaço físico independente. Isso quer dizer que os profissionais do Nasf devem utilizar o próprio espaço físico dos CSF e do seu território (BRASIL, 2012a).

\section{Consideraçôes finais}

Os desafios enfrentados pelo Nasf em sua prática no contexto da $\mathrm{ABS}$ não são pequenos, pois representam o fortalecimento de um modelo alternativo e contrahegemônico a partir da implementação de novos processos de trabalho e de açôes transformadoras. Várias foram as preocupações expressas nos discursos dos stakeholders, as quais se traduzem em aspectos que restringem a atuação do Nasf quanto ao princípio da integralidade na ABS.

A fragilidade do vínculo profissional entre as equipes, e especialmente entre os profissionais e a população, foi o principal aspecto restritivo identificado, preocupação compartilhada praticamente por todos os sujeitos envolvidos no processo avaliativo, sobretudo como resultado do elevado número de equipe de ESF vinculadas a uma mesma equipe do Nasf e, mais precisamente, do número de diferentes territórios a que as equipes estáo vinculadas, o que, agravado pela dificuldade de deslocamento entre os territórios, fragiliza sobremaneira o vínculo e, por vezes, o acesso a tais territórios.

Outro aspecto restritivo que chamou a atençáo neste estudo foi a falta de competências por parte dos profissionais para atuarem no contexto do Nasf/ABS, resultado da falta de conhecimentos, habilidades e atitudes, comprometendo o perfil profissional para tal abordagem.

Compreendemos que a atuação do Nasf quanto ao princípio da integralidade é ampla e complexa, exigindo-se, dessa maneira, que sejam implementados processos 
avaliativos de forma contínua e contextualizados, de modo a contribuir para seu aprimoramento. Tais processos devem incluir todos os sujeitos implicados no processo, para que, por meio da discussão e compreensão do objeto de estudo, possam auxiliar no fortalecimento dos processos de trabalho do Nasf, bem como fornecer elementos para futuras discussóes.

Nesse contexto, acreditamos que os resultados do presente trabalho possam vir a compor pontos de discussão e, principalmente, servir como base para açôes que visem ao aperfeiçoamento dos processos de trabalho do Nasf tendo como horizonte a integralidade do cuidado, buscando minimizar os aspectos restritivos aqui identificados para sua concretização. ${ }^{1}$

\section{Referências}

ANDRADE, L. M. B. et al. Análise da implantação dos Núcleos de Apoio à Saúde da Família no interior de Santa Catarina. Saude \& Transf Soc., v. 3, n. 1, p. 18-31, 2012.

ANJOS, K. F. et al. Perspectivas e desafios do Núcleo de Apoio à Saúde da Família quanto às práticas em saúde. Saúde Debate, v. 37, n. 99, p. 672-680, 2013.

ARAÚJO, E. M. D.; GALIMBERTTI, P. A. A colaboração interprofissional na estratégia saúde da família. Psicol. Soc., v. 25, n. 2, p. 461-468, 2013.

BARBOSA, E. G. et al. Experiência da Fisioterapia no Núcleo de Apoio à Saúde da Família em Governador Valadares, MG. Fisioter. Mov., v. 23, n. 2, p. 323-330, 2010.

BEZERRA, P. A. Atuação dos profissionais do núcleo de apoio à saúde da família no Recife: desafios e possibilidades. Dissertaçáo (Mestrado em Saúde Pública) - Fundação Oswaldo Cruz, Recife, 2013.

BONALDI, A. P.; RIBEIRO, M. D. Núcleo de Apoio à Saúde da Família: as açóes de promoção da saúde no cenário da estratégia saúde da família. Rev APS, v. 17, n. 2, p. 195-203, 2014.

BOOT, E. Favourites and others: reflexivity and the shaping of subjectivities and data in qualitative research. Qualitative Research, v. 10, n. 2, p. 159-173, 2010.

BOSI, M. L. M.; MERCADO, F. J. (Orgs.). Avaliação qualitativa de programas de saúde: enfoques emergentes. Petrópolis: Vozes, 2006.

BOSI, M. L. M.; UCHIMURA, K. Y. Avaliação qualitativa de programas de saúde: contribuiçóes para propostas metodológicas centradas na integralidade e na humanizaçáo. In: BOSI, M. L. M.; MERCADO, F. J. (Orgs.). Avaliação qualitativa de programas de saúde: enfoques emergentes. Petrópolis: Vozes, 2006. p. 87-117. 
BRASIL. Ministério da Saúde. Secretaria de Atenção à Saúde. Departamento de Atenção Básica. Política Nacional de Atenção Básica (PNAB). Brasília: Ministério da Saúde, 2012a.

. Ministério da Saúde. Secretaria de Atenção à Saúde. Departamento de Atenção Básica. Diretrizes do NASF - Núcleo de Apoio à Saúde da Família. Brasília: Ministério da Saúde, 2009 (Cadernos de Atenção Básica, n. 27).

. Ministério da Saúde. Secretaria de Atenção à Saúde. Departamento de Atenção Básica. Núcleo de Apoio à Saúde da Família: ferramentas para a gestão e para o trabalho cotidiano. Brasília: Ministério da Saúde, 2014. (Cadernos de Atenção Básica, n. 39).

. Portaria no 3.124, de 28 de dezembro de 2012. Redefine os parâmetros de vinculação dos Núcleos de Apoio à Saúde da Família (NASF) Modalidades 1 e 2 às Equipes Saúde da Família e/ou Equipes de Atenção Básica para populaçóes específicas, cria a Modalidade NASF 3, e dá outras providências. Diário Oficial da União, 28 dez. 2012b.

. Resolução no 466, de 12 de dezembro de 2012. Conselho Nacional de Saúde. Comissão Nacional de Ética em Pesquisa. Normas regulamentadoras de pesquisa envolvendo seres humanos. Brasília: Ministério da Saúde, 2012c.

CAMPOS, G. W. S. Um método para a análise e cogestão de coletivos: a constituição do sujeito, a produçáo de valor de uso e a democracia em instituiçôes: O Método da Roda. São Paulo: Hucitec, 2000.

CARVALHO, L. B.; BOSI, M. L. M. Tessituras de um modo "éticopolítico" do cuidado em saúde mental. In: NUNES, M.; LANDIM, F. L. P. (Orgs.). Saúde mental na atenção básica: política e cotidiano. Salvador: Editora Edufba, 2016.

CASTRO, A. L. B.; MACHADO, C. V. A política federal de atenção básica à saúde no Brasil nos anos 2000. Physis: Revista de Saúde Coletiva. Rio de Janeiro, v. 22, n. 2, p. 477-506, 2012.

CECILIO, L. C. O. et al. Atenção Básica à Saúde e a construçấo das redes temáticas de saúde: qual pode ser o seu papel? Cien Saude Colet. Rio de Janeiro, v. 17, n. 11, p. 2893-2902, 2012.

CONSELHO NACIONAL DE SECRETARIAS MUNICIPAIS DE SAÚDE (CONASEMS). Atenção Básica que Queremos. Brasília: CONASEMS, 2011.

COSTA, G. D. et al. Saúde da família: desafios no processo de reorientação do modelo assistencial. Rev Bras Enferm, v. 62, n. 1, p. 113-118, 2009.

DESLANDES, S. F.; IRIART, J. A. B. Usos teórico-metodológicos das pesquisas na área de Ciências Sociais e Humanas em Saúde. Cad. Saude Publica. Rio de Janeiro, v. 28, n. 12, p. 2380-2386, 2012.

EAKIN, J. Towards a 'standpoint' perspective: Occupational health and safety from the perspective of the workers, Policy and Practice in Health and Safety, v. 8, n. 2, p. 113-127, 2010. 
FRAGELLI, T. B. O. Análise das competências profissionais no núcleo de apoio à saúde da família. Tese (Doutorado) - Universidade de Brasília, Brasília, 2013.

FURTADO, J. P. Um método construtivista para a avaliação em saúde. Ciência \& Saúde Coletiva. Rio de janeiro, v. 6, n. 1, p. 165-181, 2001.

GOMES, K. O.; COTTA, R. M. M.; ARAÚJO, R. M. A. Atenção Primária à Saúde - a "menina dos olhos" do SUS: sobre as representaçóes sociais dos protagonistas do Sistema Único de Saúde. Cien Saude Colet, v. 16, n. supl. 1, p. 881-892, 2011.

GUBA, E. G.; LINCOLN, Y. S. Avaliação de quarta geração. Campinas, SP: Editora da Unicamp; 2011.

HEIMANN, L. S.; IBANHES, L. C.; BOARETTO, R. C. Atenção primária em saúde: um estudo multidimensional sobre os desafios e potencialidades na Região Metropolitana de São Paulo (SP, Brasil). Cien Saude Colet. Rio de Janeiro, v. 16, n. 6, p. 2877-2887, 2011.

HENRIQUE, F.; CALVO, M. C. M. Grau de implantação do Programa Saúde da Família e indicadores sociais. Cien Saude Colet. Rio de Janeiro, v. 14, n. sup. 1, p. 1359-1365, 2009.

LEITE, D. F.; NASCIMENTO, D. D. G.; OlIVEIRA, M. A. C. Qualidade de vida no trabalho de profissionais do NASF no município de São Paulo. Physis: Revista de Saúde Coletiva. Rio de Janeiro, v. 24, n. 2, p. 507-525, 2014.

LIMA, M. L. L. T. et al. Assistência em reabilitação para vítimas de acidentes e violência: a situação dos municípios em Pernambuco, Brasil. Cien Saude Colet. Rio de Janeiro, v. 17, n. 1, p. 33-42, 2012.

LINHARES, J. H. et al. Análise das açôes da Fisioterapia do NASF através do SINAI no município de Sobral-CE. Cadernos ESP, v. 4, n. 2, p. 32-41, 2010.

MACHADO, M. F. A .S.et al. Integralidade, formação de saúde, educação em saúde e as propostas do SUS: uma revisão conceitual. Cien Saude Colet. Rio de Janeiro, v. 12, n. 2, p. 335-342, 2007.

MATTOS, R. A. A integralidade na prática (ou sobre a prática da integralidade). Cad. Saude Publica. Rio de Janeiro, v. 20, n. 5, p. 1411-1416, 2004.

MERHY, E.E. Saúde: a cartografia do trabalho vivo. São Paulo: Hucitec, 2002.

MINAYO, M. C. S. O desafio do conhecimento: pesquisa qualitativa em saúde. Sáo Paulo: Hucitec, 2007.

MOLINI-AVEJONAS, D. R.; MENDES, V. L. F.; AMATO, C. A. L. H. Fonoaudiologia e Núcleos de Apoio à Saúde da Família: conceitos e referências. Rev Soc Bras Fonoaudiol., v. 15, n. 3, p. 465-474, 2010. 
NASCIMENTO, C. M. B. Núcleo de apoio à saúde da família: uma análise da atenção à saúde em municípios da região metropolitana do recife. Tese (Doutorado em Saúde Pública) Fundação Oswaldo Cruz, Recife, 2014.

NASCIMENTO, D. D. G.; OLIVEIRA, M. A. C. Reflexões sobre as competências profissionais para o processo de trabalho nos Núcleos de Apoio à Saúde da Família. O Mundo da Saúde, v. 34, n. 1, p. 92-96, 2010.

NOGUEIRA-MARTINS, M. C. F; BÓGUS, C. M. Consideraçóes sobre a metodologia qualitativa como recurso para o estudo das açôes de humanização em saúde. Saúde Soc., v. 13, n. 3, p. 44-57, 2004.

PATrocíniO, S. S. S. M. Núcleo de Apoio à Saúde da Família: proposta nacional e a implementação em municípios do estado do Rio de Janeiro. Dissertação (Mestrado em Saúde Pública) - Escola Nacional de Saúde Pública Sergio Arouca, Rio de janeiro, 2012.

REIS, F.; VIEIRA, A. C. V. C. Perspectivas dos terapeutas ocupacionais sobre sua inserção nos Núcleos de Apoio à Saúde da Família (NASF) de Fortaleza, CE. Cad Ter Ocup UFSCar, v. 21, n. 2, p. 351-360, 2013.

SALA, A. et al. Integralidade e Atenção Primária à Saúde: avaliação na perspectiva dos usuários de unidades de saúde do município de São Paulo. Saúde Soc, v. 20, n. 4, p. 948-960, 2011.

SANTOS, A. P. L.; LACAZ, F. A. C. Apoio Matricial em Saúde do Trabalhador: tecendo redes na Atenção Básica do SUS, o caso de Amparo/ SP. Cien Saude Colet. Rio de Janeiro, v. 17, n. 5 , p. 1143-1150, 2012.

SILVA, A. T. C. S. et al. Núcleos de Apoio à Saúde da Família: desafios e potencialidades na visão dos profissionais da Atenção Primária do Município de São Paulo, Brasil. Cad. Saude Publica. Rio de Janeiro, v. 28, n. 11, p. 2076-2084, 2012.

STARFIELD, B. Atenção Primária: equilíbrio entre necessidades de saúde, serviços e tecnologia. Brasília: Unesco, 2002.

STRALEN, C. J. V. et al. Percepção dos usuários e profissionais de saúde sobre atenção básica: comparação entre unidades com e sem saúde da família na Região Centro-Oeste do Brasil. Cad. Saude Publica. Rio de Janeiro, v. 24, n. supl. 1, p. 148-158, 2008.

\section{Nota}

${ }^{1}$ J. D. de Araujo Neto elaborou e executou o projeto de pesquisa, coleta, análise e discussão dos resultados, redaçẫo do artigo. I. M. N. Albuquerque elaborou o projeto de pesquisa, análise e discussão dos resultados, revisão do artigo. G. V. Lira realizou a revisão crítica do artigo. M. L. M. Bosi realizou a revisão crítica e redação final do artigo. 


\section{Abstract}

Restrictive aspects of comprehensive healthcare in the Family Health Supporting Nuclei: the stakeholders' viewpoint

The Family Health Supporting Nuclei (FHSN) aim to expand and qualify health actions along with the Family Health Strategy (FHS), to consolidate the principles of the Unified Health System (SUS), as an example of comprehensiveness that still faces many challenges, among which there is the organizational culture. This study aimed to analyze the restrictive aspects of the principle of integral care. It is an evaluative study, guided by the fourth-generation approach, in the scenario of a municipality in the Northeastern Brazil. It involved managers, FHSN professionals, FHS professionals and users, totaling 27 participants. For the construction of the discursive material we used semi-structured interviews, operating the HermeneuticDialectic Circle. The empirical material gave rise to four categories: Fragility of the link with the territory; Challenges of multidisciplinary teamwork; Lack of competencies for FHSN performance and Logistic Support Disability. The study evidences as a restrictive factor of importance FHSN's actions concerning integral care, the fragility of the link between health teams and those with the population, as well as the lack of skills of professionals, whose importance is expressed in the results.

> Keywords: health evaluation; comprehensive healthcare; Primary Health Care. 